(C) 2018. This manuscript version is made available under the CCBY-NC-ND 4.o license http://creativecommons.org/licenses/by-nc-nd/4.0/ 


\section{Accepted Manuscript}

Electrical machines-based multi-disturbance device for testing distribution grid technologies

Julia Merino, Carlos Veganzones, Roberto Álvaro-Hermana, Jesús FraileArdanuy

PII: S0142-0615(17)31350-9

DOI: https://doi.org/10.1016/j.ijepes.2017.12.030

Reference: JEPE 4480

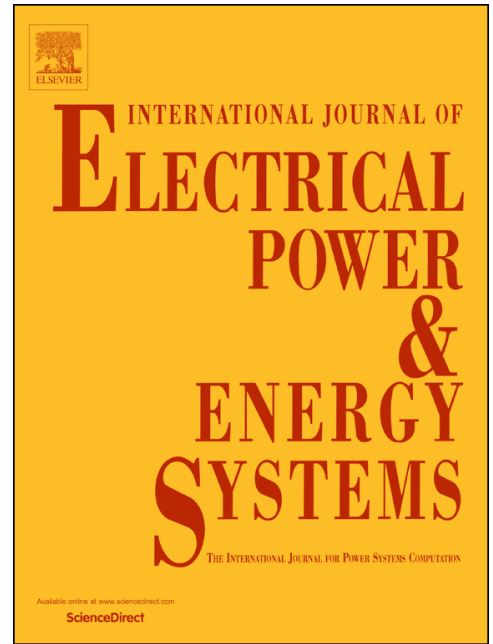

To appear in:

International Journal of Electrical Power and Energy Systems

Received Date: $\quad 30$ May 2017

Revised Date: $\quad 13$ November 2017

Accepted Date: $\quad 25$ December 2017

Please cite this article as: J. Merino, C. Veganzones, R. Álvaro-Hermana, J. Fraile-Ardanuy, Electrical machinesbased multi-disturbance device for testing distribution grid technologies, International Journal of Electrical Power and Energy Systems (2017), doi: https://doi.org/10.1016/j.ijepes.2017.12.030

This is a PDF file of an unedited manuscript that has been accepted for publication. As a service to our customers we are providing this early version of the manuscript. The manuscript will undergo copyediting, typesetting, and review of the resulting proof before it is published in its final form. Please note that during the production process errors may be discovered which could affect the content, and all legal disclaimers that apply to the journal pertain. 


\title{
Electrical machines-based multi-disturbance device for testing distribution grid technologies
}

\author{
Julia Merino $^{1}{ }^{*}$, Carlos Veganzones ${ }^{2}$, Roberto Álvaro-Hermana ${ }^{3}$, and Jesús Fraile-Ardanuy ${ }^{4}$ \\ 1 TECNALIA; julia.merino@tecnalia.com \\ 2 Universidad Politécnica de Madrid \\ 3 ORKESTRA, Fundación Deusto \\ 4 Information Processing and Telecommunications Center, Universidad Politécnica de Madrid
}

\begin{abstract}
The growth of distributed energy resources in power systems, mainly converter-coupled generators, has forced the evolution of grid codes, increasing the requirements to be fulfilled by the generators before their connection to the mains. Solving this problem is crucial to guarantee the reliability and stability of the power system. Current standards force the generators to remain connected when facing voltage and/or frequency disturbances and, in some advanced grid codes, also when the generators are facing transient phase jumps produced as a consequence of those disturbances. If considering that the increment of the distributed generation is mainly done at a distribution level, it is unrealistic to consider voltage and frequency events as decoupled phenomena in the testing and certification procedures, as it is currently done. The testing device proposed in this paper is able to reproduce voltage, frequency and phase jumps disturbances of a controlled value simultaneously, being able to reproduce the real grid behavior reliably. Its design is based on standard components with a simple control system, which makes it easily replicable and scalable up to the power of the device to be tested. Therefore, the proposed device is an interesting commercially competitive testing equipment suitable for certification.
\end{abstract}

Keywords: Distributed generation testing equipment, electrical disturbances generator, induction regulator, variable frequency transformer

\section{Introduction}

Owing to the increasing integration of renewable energy sources (RES) in electrical power systems, it was necessary for the system operators to adapt current grid codes, thereby establishing new and stricter requirements to be fulfilled for connecting the generators to the electricity networks. These standards lay down reference disturbances under which the sources have to remain connected. The disturbances are usually voltage dip/swell patterns or frequency disturbances (steps or ramps) and in some new and more advanced codes, they are even incorporating phase jump requirements [1]. The voltage dip profiles are usually defined as the envelope curves of all voltage dips registered over a given period in the electrical network where the code is going to be applied [2]. This variety of grid disturbances introduces the necessity of flexible testing equipment being capable of reproducing variable patterns, with the aim to certificate the capabilities of all convertercoupled RES before their connection to the grid. For example in the Spanish system, connection requirements are nowadays already very demanding for wind power generators [3] due to the huge amount of installed wind power capacity - approximately $22 \%$ of the total capacity-23.057 MW in 2016 [4] - Such tough voltage dip compliances are still not required in most countries, neither for wind nor for other energy sources. However, in the near future the connection of these technologies to the grid will also be committed to compliance with equally tough requirements, because the European ENTSO-E Network Code on Requirements for Generators (RfG) has been recently 
approved (May 2017). This code forces the grid operators to implement the standards in their countries in less than three years [5].

On this basis, a novel testing device for RES certification is presented in this paper. Its main advantage, which makes it unique among all the existing testing equipment [6] is the capacity to simultaneously reproduce voltage, frequency and phase jump disturbances with an electrical machines-based topology, covering all the requirements demanded by current and expected grid codes (following the ENTSO-E guidelines). The lack of power electronics avoids additional harmonic pollution on the mains. Further, the proposed equipment is also a flexible, cheap and easily scalable device. It is very appropriate for field testing, because it is based on the use of asynchronous electrical machines. The device can be easily programmed to change the disturbances to be reproduced with simple operation through a designed human machine interface (HMI).

This paper is organised as follows: Section 2 reviews the main topologies of different testing devices suitable for RES certification both at a technical-literature and commercial level, highlighting the main differences between them and the testing device proposed in this work. In section 3 the device and the operational procedure for test execution are described. Section 4 shows the implementation of an initial prototype at laboratory scale. In section 5, the testing device performance is analysed, showing different disturbances that the equipment is able to reproduce. Finally, in the last section, the main conclusions of the paper are presented.

\section{State of the art of current equipment for testing distribution grid technologies testing}

Owing to their significance explained in Section 1, topics related to the certification process and the devices required for testing and validating electrical generators before their connection to the grid have been broadly addressed for several years.

Most of the testing devices proposed today in technical literature and patents focus on different devices that are able to reproduce voltage dips/swells. Voltage dips are the most severe disturbances that a grid-connected device can experience. In the recent past, these events were responsible of the massive disconnection of primitive wind power plants based on squirrel-cage induction generators $[7,8]$. Recently, the widespread installation of distributed energy resources (DERs) into the distribution grid, which is weaker than a transmission grid, has forced the evolution of more demanding grid requirements.

There exist three main topologies of electrical disturbance generators (EDG) commonly found in literature: topologies based on impedances, on electrical machines (both static and rotating) and on power electronics converters.

\subsection{Impedance-based EDG}

Impedance-based EDG have been the most widely used due to their simplicity and robustness. However these generators are only suitable for testing low-voltage ride-through (LVRT) and highvoltage ride through (HVRT) capabilities of the equipment under test (EUT). In [9] the most extended setup for the impedance-based topology(shown in Figure 1) is analyzed. The insertion of an impedance in parallel, named $Z_{\mathrm{g}}$, at the point of common coupling (PCC) establishes an alternative current path, thereby creating a sudden voltage dip with adjustable depth that depending on the impedance value. These devices are scalable up to the EUT power. Owing to their configuration it is necessary to adjust or change the impedances for the different voltage depths, 
thereby making them an unadaptable testing setups. With the implementation of an ad hoc control of the electromechanical or static contactors the devices are able to generate single-phase, twophase or three-phase dips. In [10], the impedances in the EDG device studied belong to a threephase transformer and are also further employed for reproducing single-phase, two-phase and threephase faults. However, the equipment maintains the classical T-configuration. Thisthis device could be considered as enclosed within the first group.

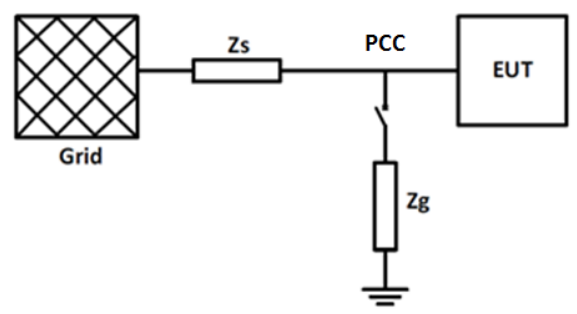

Figure 1. Impedance-based voltage dip generators

This configuration is required in LVRT/HVRT testing of wind turbines according to the international IEC 61400-21 standard [11]. In Spain, it is also the demanded configuration for testing and validating the behaviour of wind turbines and PV installations according to [12]. The main drawback of this topology is the influence that the series impedance of the testing device $\left(Z_{\mathrm{s}}\right)$ imposes on the EUT dynamics. In order to minimise this effect, the regulation establishes that in case of a short-circuit power at the PCC below 5xthe EUT power and the voltage dip profile must be obtained at the PCC through a test with the EUT loaded. Otherwise, the reactances can be adjusted in a no-load test and considered suitable for the test cases with load. Despite its limitations, this is still the most common topology used by manufacturers, such as Enercon or Gamesa, in accordance with the IEC standard. The certification of their 5MW wind turbine series is accomplished in the Wind Turbine Test Laboratory (LEA) of the Spanish National Centre for Renewable Energy (CENER) [13,14].

\subsection{Electrical machines based EDG}

Electrical machines-based EDG devices use as main element an electric machine, either static or rotating. Most of the testing equipment uses the combination of transformers with any kind of electronic power modules, such as SCRs or IGBTs [15,16] as shown in Figure 2.

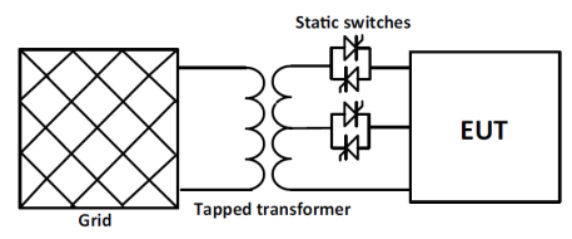

Figure 2. Transformer-based voltage dip generator

As main advantage to highlight, these devices are easily scalable, because the transformers and power electronic modules exist commercially up to the voltage and power levels that would be required by the DERs to be tested. In order to make the testing device more flexible, usually tapped transformers are employed to check several voltage dip patterns. Reference [17] uses a combination 
of a tapped transformer.With tap inductances, and with this configuration, the device can test EUTs up to $10 \mathrm{MW}$. The main advantage of these systems is that they are able to generate voltage dips, frequency disturbances and phase jumps, as the EDG device proposed in this paper. However, it can not reproduce all of them simultaneously. Within the electrical machines-based group, only two EDG devices appear in technical literature that were explored as devices using synchronous generators [18,19]. The synchronous generators present the advantage, over the simplest impedance-based ones, of being able to reproduce both voltage and frequency disturbances by adjusting field excitation and mechanical power of the turbine respectively. However, the scalability of these devices implies very high costs that make them unaffordable.This caused this topology to be relegated in the last years with no significant improvements in the regarding research area. Apart from that, only symmetrical faults can be reproduced with this topology and the synchronous machines have high ramping times (up/down). Hence the reproduction of the grid behaviour is unrealistic.

\subsection{Full-converter-based EDG}

Full-converter testing devices are, up to the present, those which have been more deeply investigated [20-23].

They are very flexible devices that can modify the amplitude of voltage, frequency and phase shift. Therefore they are suitable for performing a wide test range [24]. In this topology, there is a decoupling between the undisturbed grid and the EUT, as shown in Figure 3.

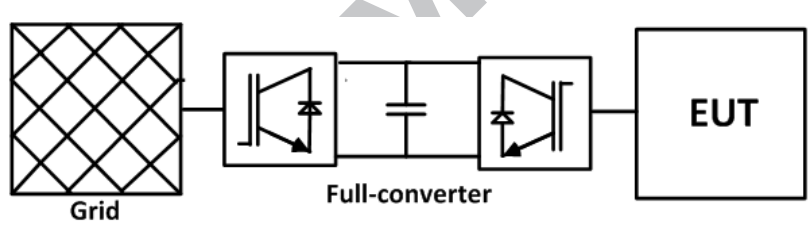

Figure 3. Standard topology of voltage dip generator based on full-power converter

The main drawback associated with full-converter testing devices is the high cost of the electronic components for big power EUT to be and a more complex control system [25]. Additionally, this equipment introduces a unnatural distortion in the voltage waveform. Owing to the currents that are supplied by the EUT during fault period, full-converter-based topologies need to have a high short circuit capacity in order to maintain a stable operation and to avoid the EUT distortion created by the grid emulator. This leads to the necessity of oversized converters to stand up against voltage disturbances. The effect can be seen in the ABB ACS 6000 [26], the mutimegawatt grid simulator of NREL [27] or the 8MW-full-converter present in the Göteborg testing site (Göteborg Wind Lab) [28]. These devices remain still implemented for low voltage levels for inverter testing and there are no commercial prototypes extensively spread for high voltage (HV) applications.

\section{Description of proposed testing device and operational procedure}

The novel testing prototype presented in this paper is composed of two coupled electrical machines (standard asynchronous machine with a wounded rotor and an ad-hoc designed electrical machine) with their associated drives, a switchgear, a control gear, and a data acquisition and 
monitoring system. As the prototype is based on electrical machines instead of power electronics, the voltage waveform exhibits no additional distortion that could potentially affect the controls of the device under test. In addition, it is a relatively inexpensive and easily scalable device based on asynchronous machines that are standard or can be standardised, thus reducing manufacturing costs. In a first approach, neglecting minor equipment and assuming similar costs for the control systems (even the control of a full-converter is highly complex), it could be concluded that this topology would be approximately $10 \%$ cheaper than their up scaled competitors based on full-converters (for a 2MW-prototype). Indicative costs have been calculated from cost breakdown of an onshore commercial wind turbine Vestas V80 with 2MW [29], where the asynchronous machine represents $3 \%$ [30], while the cost of a full power converter lies between $7 \%$ and $12 \%$ of the total costs for wind turbine [31]. If considering that the full-power converters of the testing devices are usually oversized (section 2.3.), savings for a testing device with the proposed topology can be even higher.

A general scheme of this testing device is shown in Figure 4, where the EUT has been assumed to be a wind turbine.

The first electrical machine connected to the grid is a variable-frequency transformer (VFT). A VFT is a phase-shifting transformer that operates with a controllable phase shift and, thus, is able to regulate the power flow. It is a very new electrical machine for power flow control and the first one started its operation in 2004 for interconnecting the asynchronous power systems of USA and Canada [32, 33].

The second electrical machine connected in cascade with the VFT is an induction regulator. Its possibilities were well explored in the first half of the $20^{\text {th }}$ century and several patents have been published [34-36]. The induction regulator is an economical, robust and easily scalable device. In spite of this, its use in industry has been infrequent (only to regulate voltage levels in electrical power systems, in railway electric traction or to control the voltage of a feeder) but the development of tapped transformers eventually replaced it [37,38]. Currently, there exists no testing device topologies using an induction regulator (see Section 2). The induction regulator is a classical asynchronous machine with a wound rotor that is blocked and the angle between both windings is controlled. By using a servodrive linked to the rotor, a continuous rotor/stator angle adjustment is achieved and full reproduction of any voltage profile, with any depth and recovery ramp can be done regardless of the grid code. The device proposed in this paper thus allows simultaneous reproduction of different types of disturbances (voltage dip/swell + frequency disturbances + controllable phase jumps). The design of the induction regulator in this prototype is intended to decouple the operation of the EUT and the disturbance generator. Thereby the design limits the impact of the EUT current injection on the disturbance generator and, thus, avoids the need to oversize the testing device, as happened with full-power converter devices (see section 2.3.).

As the proposed testing device can reproduce all above-mentioned disturbances simultaneously, it is especially suitable to emulate the real behaviour of distribution grids, where the high $R / X$ ratio does not allow the decoupling of voltage and frequency disturbances. Hence, DERs can be tested under real-field conditions. 


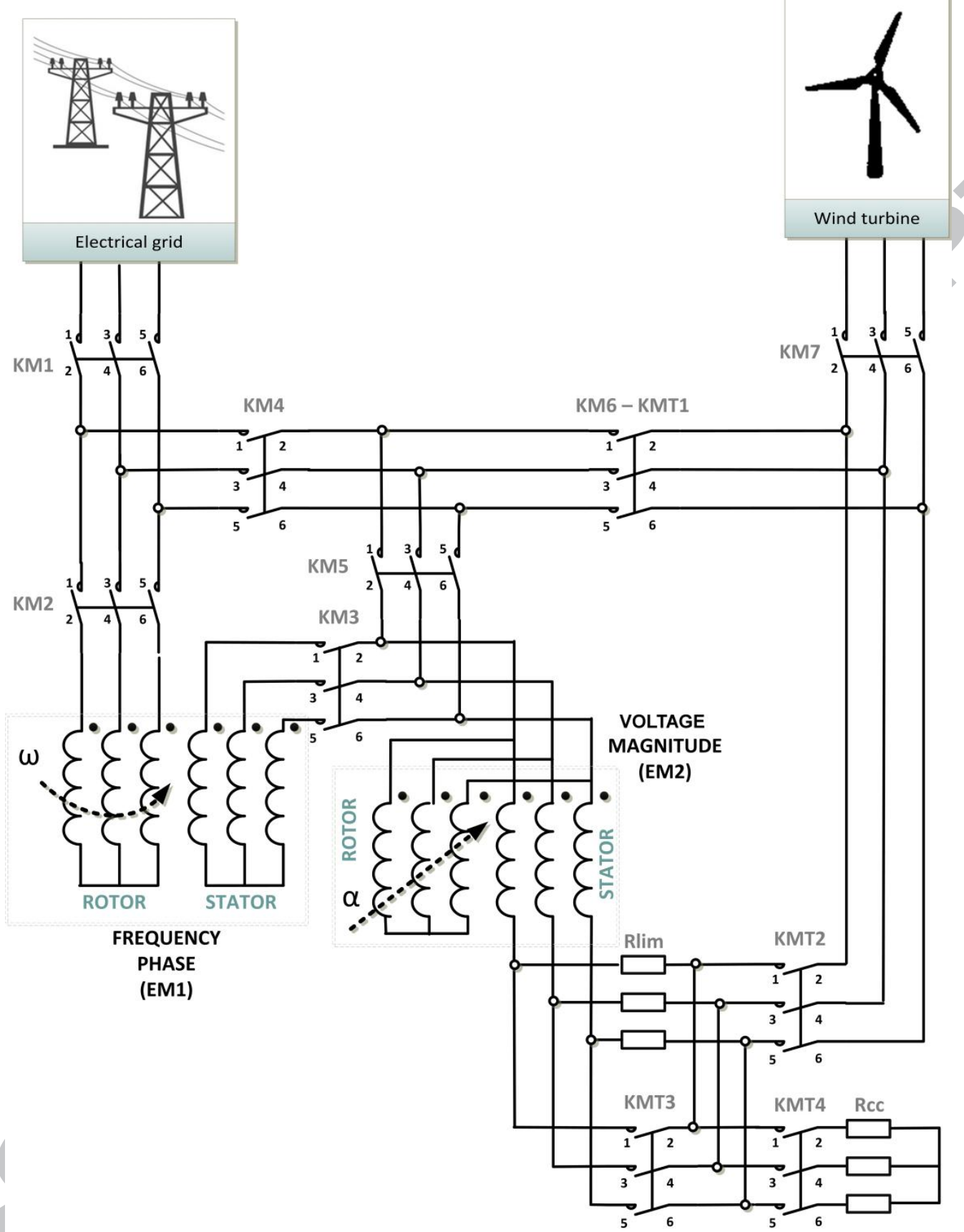

Figure 4. General scheme of the proposed testing device

The testing device is placed between the mains (through contactor KM1 in the figure) and the DER to be tested (through contactor KM7). The electrical machine EM1 (the VFT) is powered by the main grid and is responsible for the phase jumps and frequency disturbances. Even the EM1 is a VTF, its functions in the testing device are twofold and none of them comprises the power flow control: 1) it modifies the frequency of the mains and 2) sets an initial angle to create a controlled phase jump. The control system acts on a servodrive that, by using of a servomotor adjusts the initial angle between rotor and stator axis as well as the rotational speed $(\omega)$ of the machine . 
The induction regulator, EM2, creates voltage magnitude disturbances. The rotor and the stator windings are connected as shown in Figure 5. The rotor is not freely moving but controlled by a servodrive linked to a servomotor. Hence, a simple buck-boost device can be obtained, and the voltage applied to the EUT, $\underline{U}_{0}$, is the difference between rotor $\left(\underline{U}_{\mathrm{r}}\right)$ and stator voltages $\left(\underline{U}_{\mathrm{s}}\right)$, as shown in Eq. (1). The single-phase scheme of the induction regulator connection is shown in Figure 5 (a) and the corresponding phasor voltage diagram for two different shaft positions is displayed in Figure 5(b).

$$
\underline{U}_{o}=\underline{U}_{r}-\underline{U}_{S}
$$

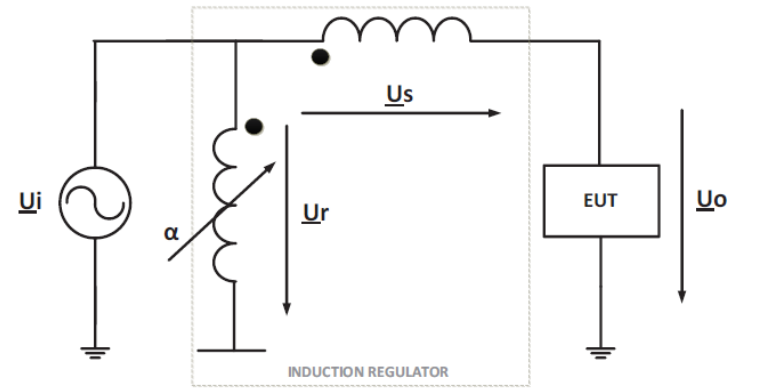

(a)

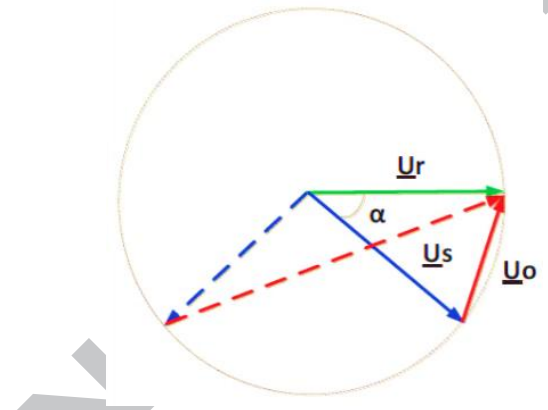

(b)

Figure 5. (a) Single-phase diagram of induction regulator EM2. (b) Voltage phasor diagram

Equation (1) can be rewritten as equation (2), applying the law of cosines to the phasor diagram (see Figure 5(a)), considering the relationship between the stator and rotor voltages through the transformation ratio $(k)$ and the relative position between the coil of a rotor phase and the corresponding coil of the stator phase $(\alpha)$,.

$$
\underline{U}_{o}^{2}=\underline{U}_{r}^{2} \cdot\left(1+k^{2}-2 \cdot k \cdot \cos (\alpha)\right)
$$

In order to get the depth in the lower part of the dip as close as possible to zero (as required in many grid codes), the value of the transformation ratio must be close to unity. Therefore it can be assumed, without committing a noticeable error, that the output voltage of the induction regulator can be approached by a more simple expression (Equation (3))

$$
\underline{U}_{o}=\underline{U}_{r} \cdot \sqrt{2(1-\cos \alpha)}
$$

The control program for the proposed testing device has been developed in a Matlab/Simulink ${ }^{\circledR}$ environment through its real-time interface (RTI) for hardware-in-the-loop simulations with dSPACE DS1104 boards. Each of the servomotors, SM1 and SM2, which drives each electrical machine, has been controlled by a cascade control with two nested loops, as shown in Figure 6. 


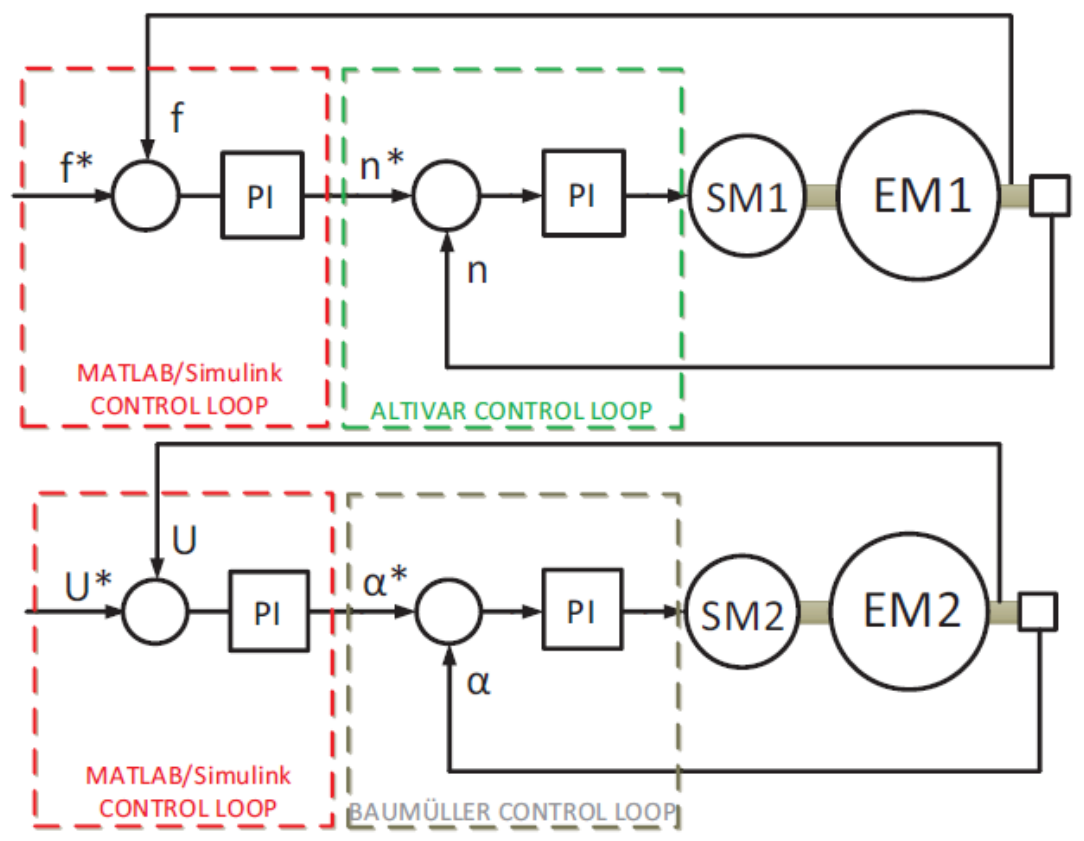

Figure 6. Control loops for the electrical machines of the testing device

The use of a cascade structure grants a better control of the primary variable which is less affected by external disturbances. The Matlab/Simulink ${ }^{\circledR}$ controllers have been developed for its implementation into the dSPACE DSP boards, which operate as master controllers, while Schneider Altivar and Baumüller seryo drives (SM1-SM2) control the internal loops, behaving as slaves. For the VFT (EM1), the difference between measured frequency in Hertz from $(f)$ and the set-point $\left(f^{*}\right)$ given by the user sets the speed reference $\left(n^{*}\right)$ in rpm for the servomotor SM1. The frequency is estimated through the recording of the voltage curve and the use of a PLL. In a similar way, the comparison between measured voltage $\left(U_{o}\right)$ and reference voltage $\left(U^{*}\right)$ in the induction regulator, EM2, results in the generation of the set-point rotor-stator angle $\left(\alpha^{*}\right)$ for the servomotor SM2.

The implementation of the control in Matlab/Simulink® has been accomplished in a block structure that can be identified in Figure 7.

- Block A: Initial calibration

- Block B: Generation of voltage dips

- Block C: Max./min. voltage and angle values from calibration

- Block D: PI controller for voltage magnitude disturbances

- Block E: Frequency disturbances and phase jump block generation

- Block F. Measurement acquisition system and sensoring calibration

- Block G: Operation of cabinet switches 


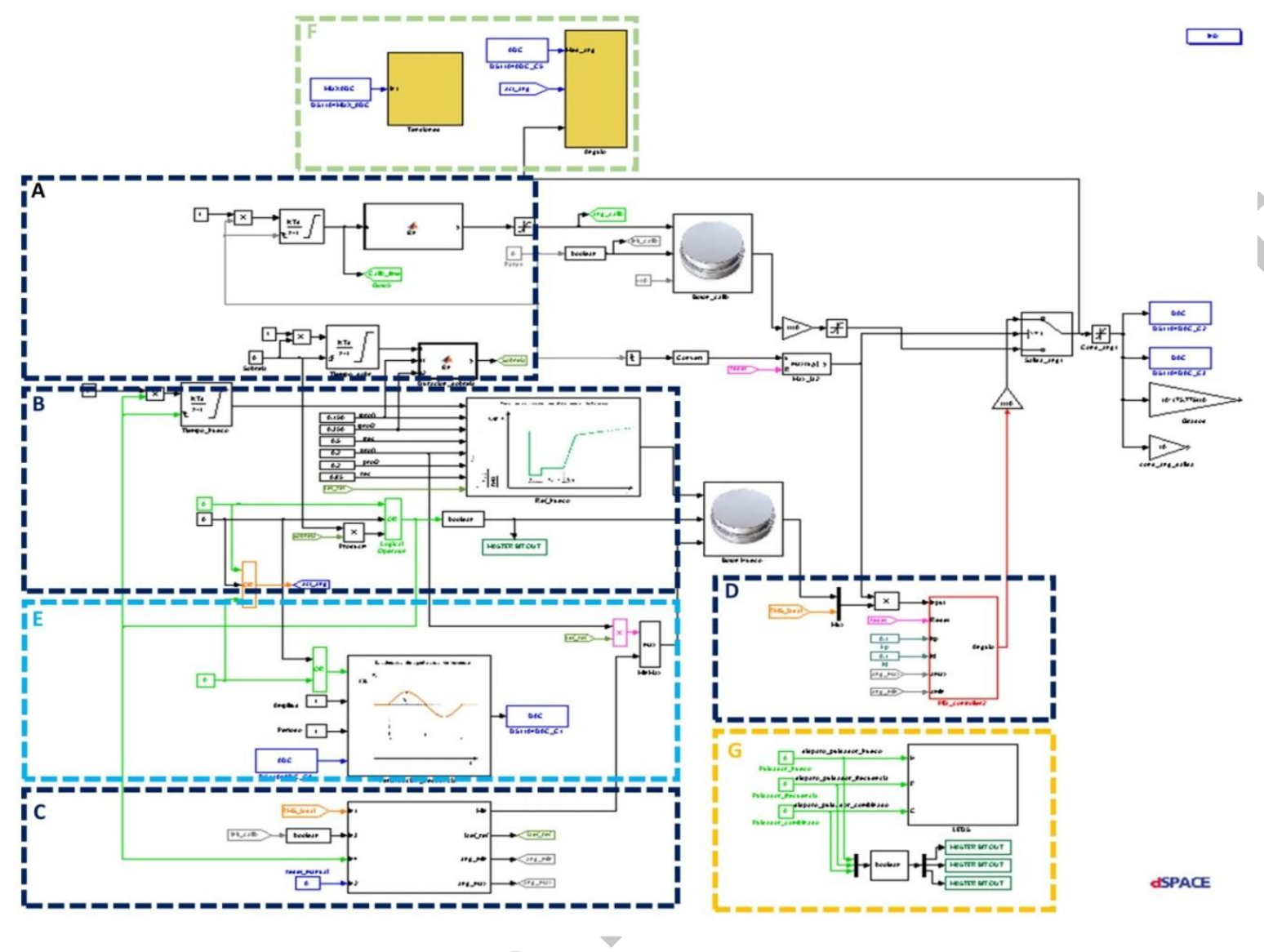

Figure 7. Matlab/Simulink® control

In order to operate the proposed testing device, the selection of the disturbance to be applied must be done. If a voltage dip/swell is required for the test, the selectable parameters of this equipment are the following: the step magnitude, span and recovery ramp. If a frequency disturbance is required, multiple patterns such as steps, ramps, or swings can be selected by the testing equipment user. Additionally, the selection of an initial phase shift is feasible. The logic associated to the contactors allows an independent operation of the two electrical machines.

When the test to be performed involves the operation of the induction regulator EM2, a preliminary process that has been included in the operation program must be conducted. This test is intended to find the angles $0^{\circ}$ and the angle $180^{\circ}$ of the rotor shaft, which will be later used as a variable parameter to determine the depth of the voltage magnitude disturbance. In a 4-pole machine and in a complete turn, two maximum and minimum values are reached. Ideally, the minimum voltage in the output of the induction regulator would be zero and the maximum would be 2 p.u. However, this would only happen in the case of full compensation of the rotor and stator e.m.f.'s and considering zero-internal voltage drop. As this is not feasible in a practical way, the calibration to find and store the real minimum and maximum voltage levels as well as their associated angles is essential. Once the calibration process is completed, the testing device remains in a standby position at the angle that gives the pre-fault voltage value and waits for the control program triggering signal. If the selected disturbance is a voltage dip/swell, the contactor KM6KMT1 suddenly opens and, simultaneously, contactor KMT2 closes (see Figure 4). The resistor $R_{\text {lim }}$ is installed in the equipment to avoid a short-circuit associated to the open-close transient process. 
An instant later, the contactor KMT4 closes and opens, causing a very brief short-circuit through resistor $R_{\mathrm{cc}}$ and thus, producing an initial sharp drop of the voltage dip. If required, the connection to the $R_{\mathrm{cc}}$ neutral point can be grounded, in order to receive zero voltage for zero-voltage ride-through testing (ZVRT). Otherwise, the internal drop of the induction regulator settles the minimum of the voltage depth.

After this sequence of contactor operation, the EUT remains connected to the output of the induction regulator, EM2, with closed contactors KM4 and KM5. In addition, the angle control takes the lead to reproduce the full voltage dip pattern. If EM1 is connected in cascade, also the frequency and phase jumps disturbances are applied (in this situation, contactor KM5 remains open and KM2 and KM3 are closed). A simplified flowchart of the operational procedure for creating the voltage disturbances is shown in Figure 8:

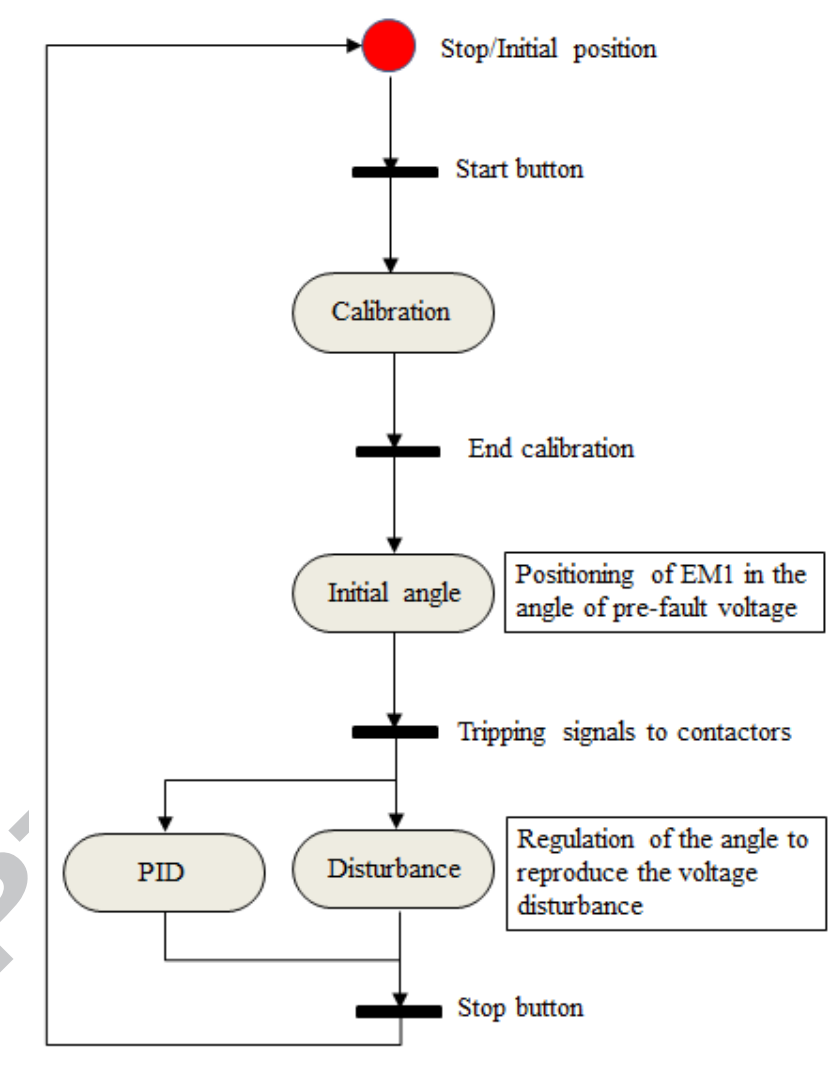

Figure 8. Diagram of voltage disturbance operation mode.

The dynamic of the proposed system is highly non-linear and the request to the PI controller regarding the voltage magnitude is extreme. The disturbances occur during a sudden change of the set-point, which seriously affects the performance of the PI controller. The proposed controller was designed by including an anti-windup back-calculation algorithm with tracking to prevent the integrator wind-up when actuator saturation occurs. 


\section{Experimental setup}

A commercial asynchronous machine has been used for the VTF (EM1). However, the special implications of the induction generator have required a specific electromagnetic design in order to match the operational requirements of the testing device. The EUT connected to the output of the induction regulator determines a fixed circulating current by the stator of EM2. That value responds to the load levels established by the national regulations or the verification and validation procedures linked to the grid codes. For example, in Spain, the regulation currently in force for the mainland territory, PVVC 12.3, settles load values of 10-30\% when the EUT is partially loaded and over $80 \%$ at full load [12]. In other countries, such as Great Britain, the validation tests have to be always conducted with a fully loaded EUT (a wind turbine, in this case) [11]. The current flow in the EM2 machine causes an internal voltage drop. This voltage drop establishes the minimum voltage dip depth that can be reached with this prototype, regardless of the profile settled by the user. The problem appears because, depending on the EUT, the remaining voltage at the output of the testing device can be higher than the grid code to test compliance with required voltage. that the sane happens in impedance-based commercial prototypes or in electrical-machine based prototypes (see section 1) where specific adjustments of the controller parameters have to be done according to the validation code in order to minimise the effect for any test. To overcome this problem, the testing prototype has been designed with an ad-hoc induction regulator ( $5 \mathrm{kVA}$ ) with a specific design that optimises the ampere-turns ratio and reduces leakage fluxes in the electrical machine with a dedicated electromagnetic slot shaping and air gap sizing.

A schematic view of the main constituent parts in this testing prototype as well as the control and monitoring system is presented in Figure 9. The green arrows represent the relations between components through control signals and the dark blue lines represent the test points where measurements are collected for monitoring (output voltage of EM1 for frequency measurements and a resolver in the EM2 shaft for angle measurement).

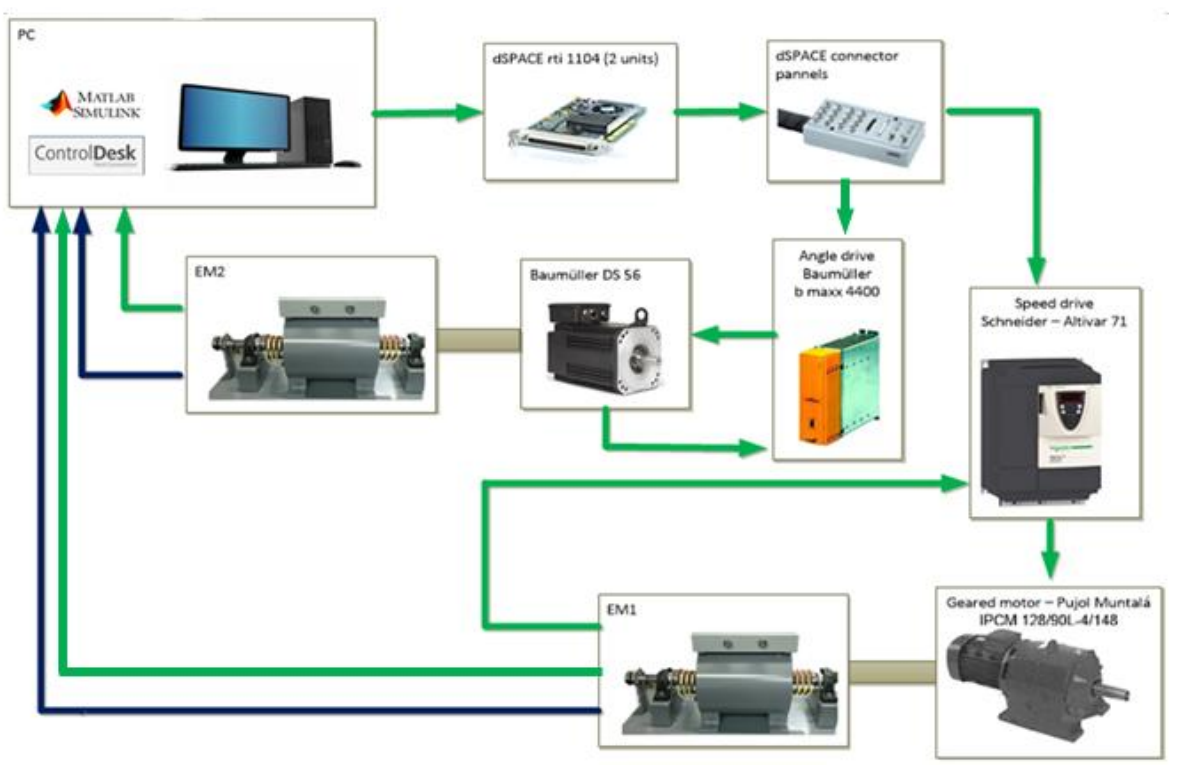

Figure 9. Scheme of electric drive system 
The control system is based on two dSPACE DS1104 R\&D controller boards used for realtime implementation of the closed control loops. They are responsible of controlling the set of electromagnetic contactors as well as the reproduction of the disturbances and have been programmed, with Matlab/Simulink ${ }^{\circledR}$ as previously mentioned. The associated dSPACE software (ControlDesk Next Generation) has been used for the development of the HMI to allow the user an easy and intuitive handling of the testing device.

The DSPs, switchgear and control gear are integrated in an electrical cabinet. As the voltage generator is intended to be used as a field-test device, compactness is one of the most valuable characteristics for the prototype. The lab setup is shown in Figure 10:

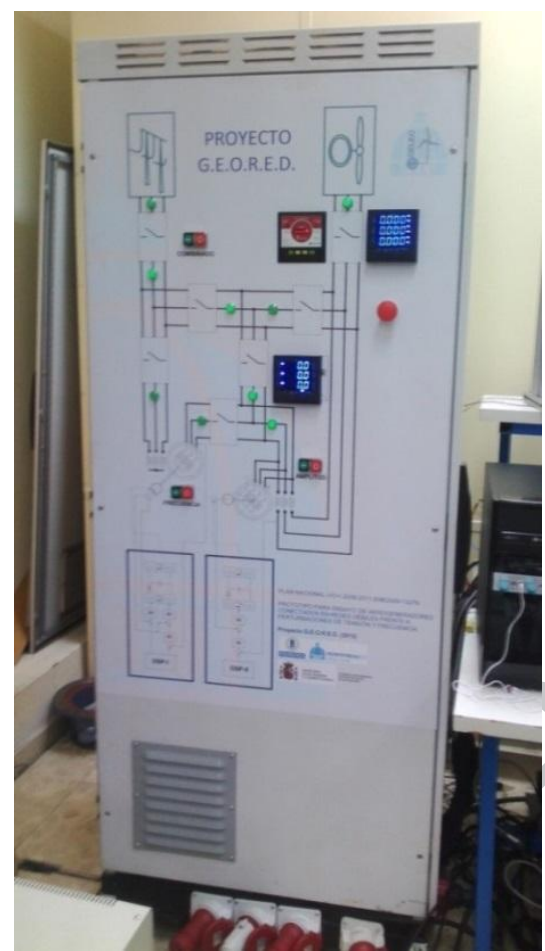

(a)

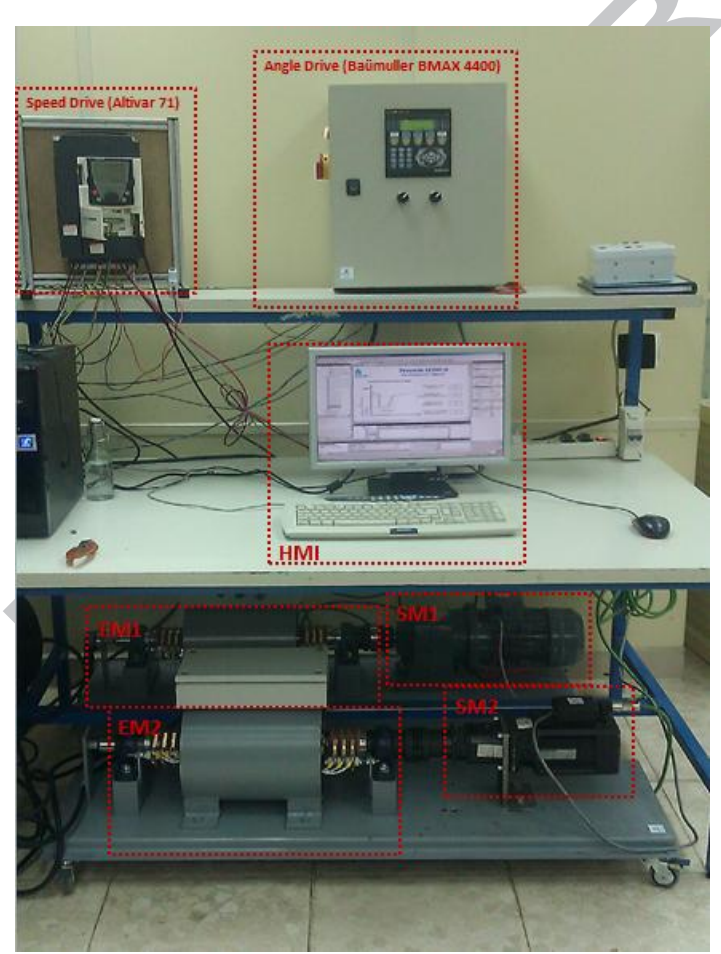

(b)

Figure 10. Laboratory setup of testing device prototype. (a) Electrical cabinet. (b) Electrical machines, drives, and HMI/operator screen.

\section{Performance evaluation of the prototype}

\subsection{Frequency disturbances}

The programming of the SM1 drive allows the reproduction of frequency disturbances in a range of $\pm 5 \mathrm{~Hz}$ with EM1 (VFT). This range is sufficient for EUT testing according to any grid code [39] applicable to an interconnected system but also to isolated systems where the requirements are tougher. Two general profiles, corresponding to frequency ramps and swells have been initially programmed. They are depicted in Figure 11, where set-point signals and the corresponding outputs are represented. Frequency steps can also be feasible realised with smaller ramping times and, in general, any other profile could be easily programmed and incorporated to the testing device if needed. 


\section{ACCEPTED MANUSCRIPT}
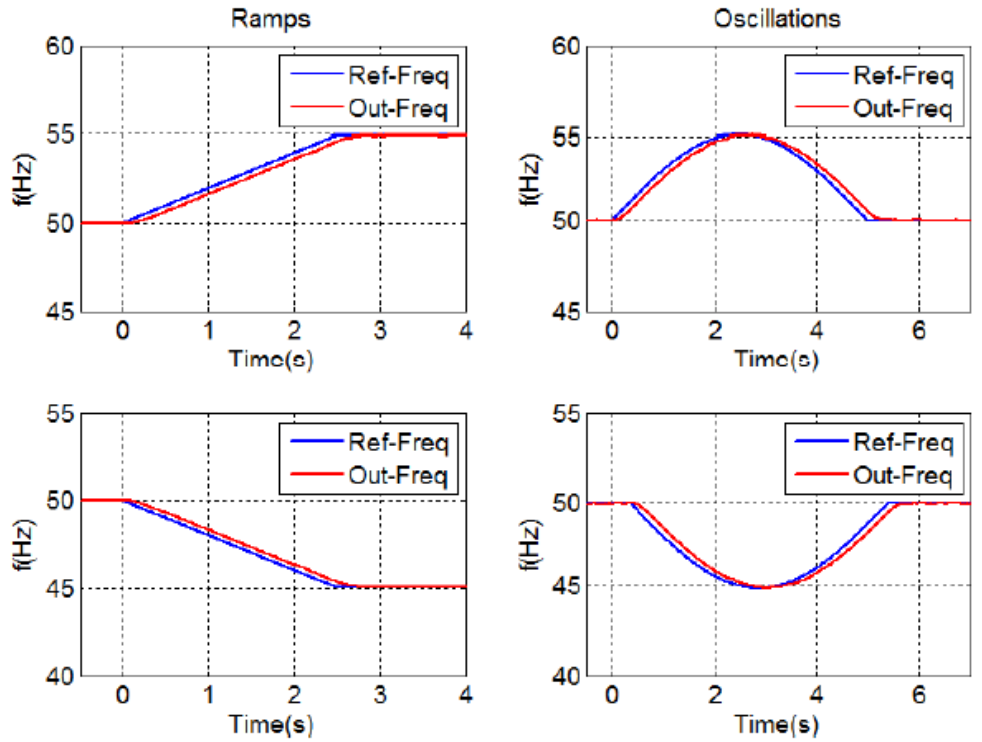

Figure 11. Sample ramp and oscillation during under/over-frequency disturbances

\subsection{Voltage disturbances}

An example of the reproduction of over/under-voltage disturbances used for testing LVRT and HVRT compliance as well as voltage dips is shown in Figure 11(a) and Figure 11(b).

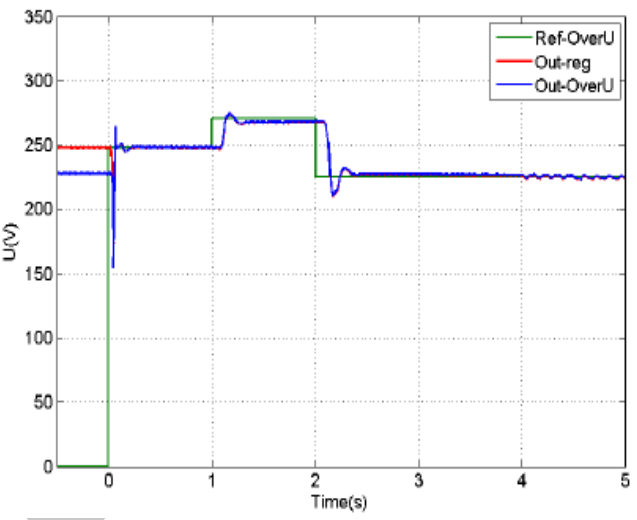

(a)

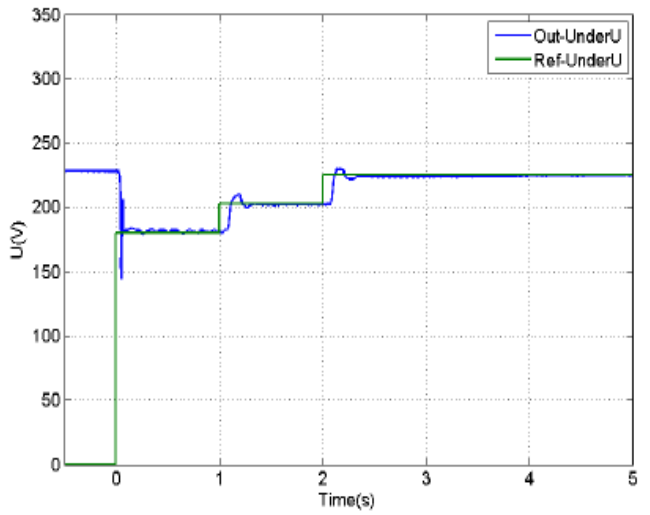

(b) 


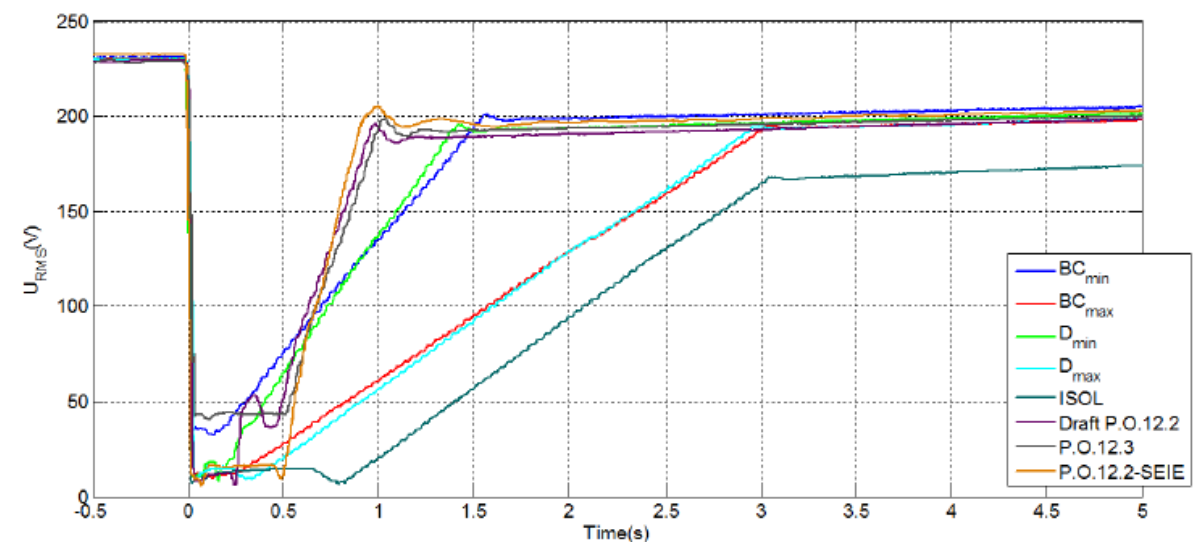

(c)

Figure 12. Voltage disturbances. (a) Voltage swell (b) Voltage dips with rectangular profile. (c)

Several voltage dips regarding different grid codes.

A selection of feasible profiles that can be reproduced with the proposed device can be observed in Figure 12(c), where the maximum and minimum B, C and D profiles are those required in the ENTSO-E code [5]. P.O.12.3. makes reference to the current standard applied for mainland territories in Spain [3], while P.O.12.2.-SEIE refers to the grid code for Spanish overseas territories [40]. Finally, draft P.O.12.2. is a Spanish code that could be applicable in the near future [41] and ISOL is a general profile that would be the evolving curve of the main grid codes in isolated territories [33]. The ZVRT is obtained with direct grounding of the $R_{\mathrm{cc}}$ neutral point. Otherwise, the voltage depth is determined by the internal drop of EM1. With the specific electromagnetic design of the induction regulator this remaining voltage is approximately $4 \%$ of the nominal voltage, thus permitting the reproduction of all the existing patterns in the grid codes. In Figure 12(a) and (b) the voltage reference set-points and the tracking curves have been included. Additionally, in Figure 12(a) the output voltage in the induction regulator after calibration stage is shown. The angle is set in accordance with the corresponding voltage to be applied to the EUT after the contactors operation. Regardless of the rise time and overshoot, it can be observed that there is a constant delay when tracking the reference for approximately $100 \mathrm{~ms}$. The servomotor has measures the angle internally to perform the inner loop control for the voltage disturbance (see Figure 6). To have external access to the inner control loops to analyse the reproduction delay of the disturbance, an analogous resolver that gives a $0-10 \mathrm{~V}$-voltage level proportional to angle $\alpha$ has been installed in the benchmark of EM1. It can be concluded that the delay appears as systematic errors linked to the commercial servodrives SM1 and SM2. However, this delay has been considered in the control program to avoid its impact on the regulation. Thus, the disturbances last as required for the codes and the delay has no effect on the final device response. The delays in the voltage measurement and in the frequency estimation by means of the PLL have been also properly compensated in the control program, avoiding an addition of extra lags to the mechanical delays.

In Figure 13 the inner control loop of EM2 has been plotted and the abovementioned delay can be observed (see also Figure 6). 


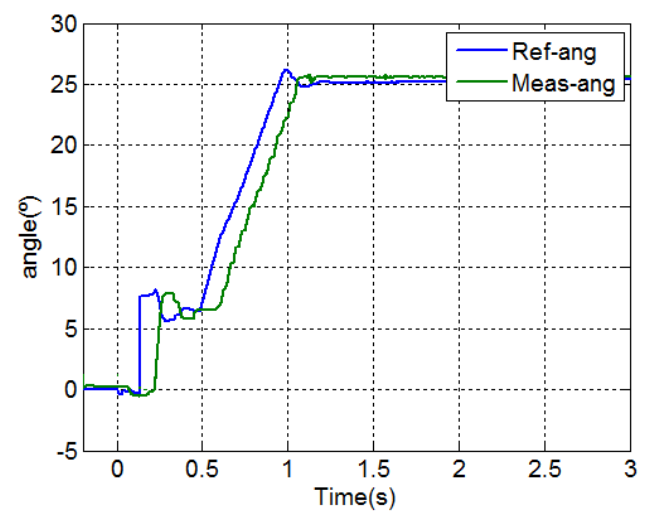

Figure 13. Angle set-point and tracking in SM2/EM2

The delay, a consequence of the performance of the commercial regulator, it is analysed for a performance evaluation of the testing device which does not have a direct impact over the EUT. As the prototype is used for offline testing and certification processes, response speed is not a requirement of priority. As it is present in both regulators, the delay has no effects on the final disturbance applied to the EUT, which will have the extension set by user according to the relevant grid code.

\subsection{Combined disturbances}

For demonstrative purposes, a multi-disturbance of voltage, frequency and a phase jump is created with the device the results are displayed in Figure 14. In Figure 14(a) the RMS voltage setpoint and tracking can be seen. It must be kept in mind that up to the starting time of the disturbance $(t=0 \mathrm{~s})$, the EUT is connected to the grid through contactors KMT4 and KM6-KMT1 and only after the disturbance has been launched, the EUT is connected to the grid through the EM1 and EM2 machines. As a summary of the full operation sequence, the voltage applied to the EUT (green line) is effectively the full-voltage dip profile while the reference (blue line) only exists after $t=0 \mathrm{~s}$. In Figure 14(b) the reference signal and tracking of the frequency disturbance is displayed. Finally, in Figure 14(c) the pre-fault phase jump together with the phase jump are shown. The later occurs naturallybecause of the modification of the circuit impedances in case of a fault. The pre-fault value is the controllable part of the phase jump which is added by the testing device according to the testing device operator requirements. 


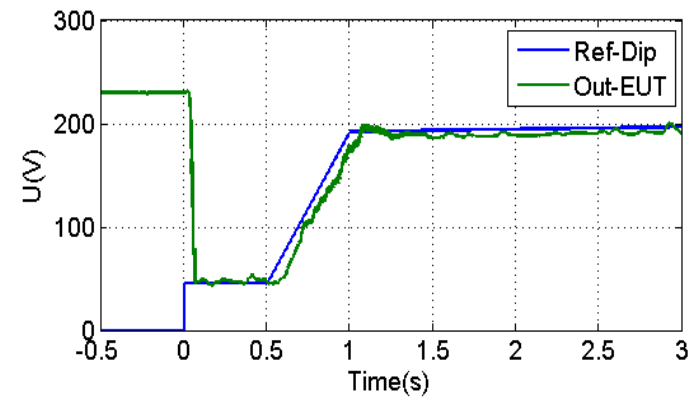

(a)

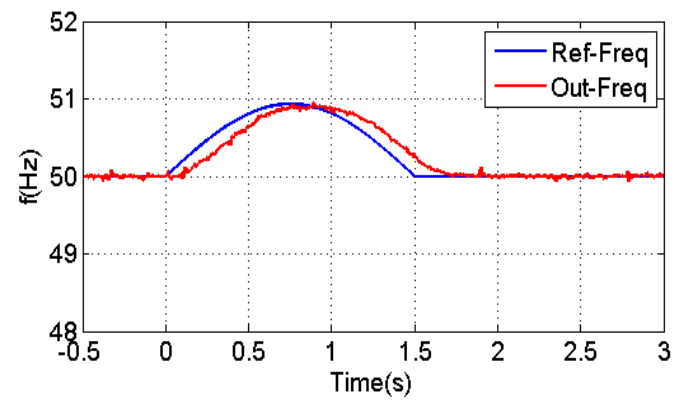

(b)

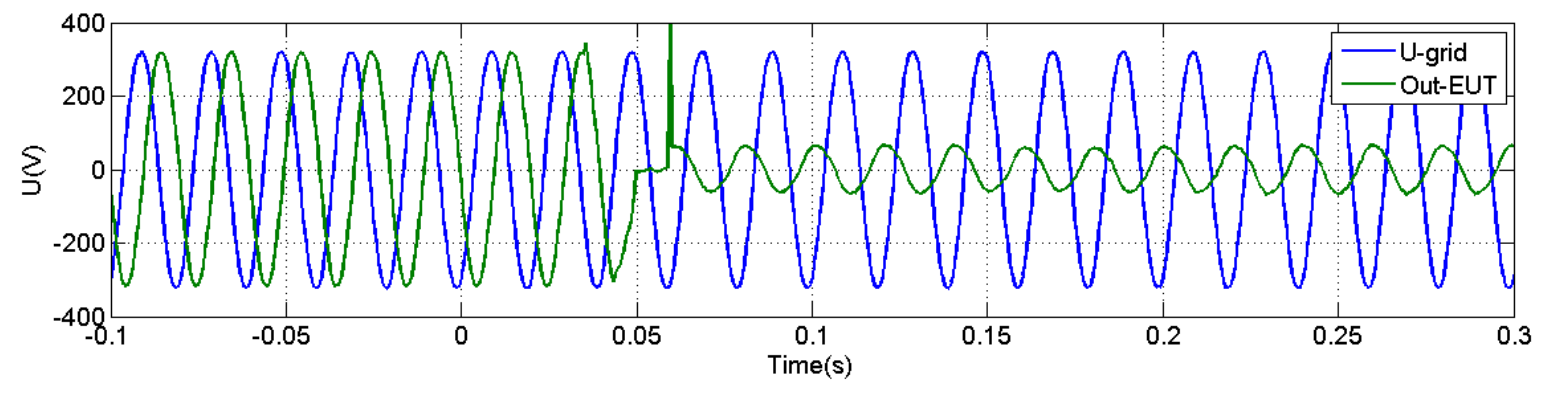

(c)

Figure 14. Multi-disturbance reproduced with testing device. (a) RMS voltage set-point and tracking. (b) Frequency set-point and tracking. (c) Voltage curves: undisturbedgrid vs. disturbed grid at the prototype output.

\section{Conclusions}

The expected growth of the distributed generation, mainly intermittent, in electrical systems has forced a tightening of the requirements in the grid codes. This forces the need to develop advanced but flexible devices capable of validating the behaviour of the new distribution grid technologies prior to their connection to the electric network. Among all the topologies that have been proposed in technical literature, only a few of them are commercially available. They are mostly based on voltage dividers, with a T-configuration for LVRT/HVRT testing. Promising progresses are being accomplished in the use of full converter topologies for implementation at a bigger scale. Even these devices are common in research and development labs, regarding low voltage levels for invertertesting in distributed generation, the devices are still not commercially spread at HV levels due to their more complex control and higher costs. In this paper, a novel proposal for a testing device based on induction machines has been presented. It is able to serve as testing device suitable for certification as it is easily scalable with standard electrical machines. It allows the reproduction of all voltage patterns, frequency disturbances and phase jumps required by regulations with a much simpler control than compared with full-converter topologies. In this work, the topology as well as its operational procedure have been presented. Finally, the implementation and preliminary tests done with a 5kVA-prototype have been reported as a proof-of-concept.

\section{Acknowledgments:}


This work has been funded by the Spanish Ministry of Economy and Competiveness under research grants PN-ENE2009-13276 and BES-2010-034386.

\section{Symbols and abbreviations}

DER Distributed energy resources

EDG Electrical Disturbances' generator

EUT Equipment under test

HMI Human machine interface

HVRT High voltage ride through

IGBT Insulated gate bipolar transistor

LVRT Low voltage ride-through

PCC Point of common coupling

PLL Phase locked loop

RES Renewable energy sources

RfG Requirements for generators

RTI Real-time interface

SCR Silicon controlled rectifier

VFT Variable frequency transformer

ZVRT Zero voltage ride through

\section{References}

[1] Energinet, Technical Regulation 3.2.5. for Wind Power Plants with a Power Output Greater than $11 \mathrm{~kW},(2010)$.

[2] M. Tsili, S. Papathanassiou, A Review of Grid Code Technical Requirements for Wind Farms, IET Renewable Power Generation. 3 (2009) 308-332. doi:10.1049/iet-rpg.2008.0070.

[3] Red Eléctrica de España (REE), Requisitos de Respuesta Frente a Huecos de Tensión de las Instalaciones Eólicas, (2006).

[4] Red Eléctrica de España (REE), Las Energías Renovables en el Sistema Eléctrico Español 2016,

http://www.ree.es/sites/default/files/11_PUBLICACIONES/Documentos/Renovables-2016v3.pdf (accessed August 29, 2017).

[5] ENTSO-E, Network Code on Requirements for Grid Connection Applicable to all Generators (RfG), (2016).

http://eur-lex.europa.eu/legal-content/EN/TXT/?uri=OJ:JOL_2016_112_R_0001.

[6] J. Merino, C. Veganzones, C.A. Platero, S. Martínez, F. Blázquez, J. Á. Sánchez, J. Rodríguez, D. Ramírez, N. Herrero, Generador de Perturbaciones de Tensión para Ensayo de Equipos Eléctricos y su Procedimiento de Operación en Redes con Generación Distribuida, ES2494592 (A1), 2014.

[7] I. Erlich, U. Bachmann, Grid Code Requirements Concerning Connection and Operation of Wind Turbines in Germany, in: IEEE, San Francisco, CA, USA, 2005: pp. 1253-1257. doi:10.1109/PES.2005.1489534.

[8] A. Dahlgren, C. Klippel, A. Juntti, Recorded Fault Ride Through Capability for Two Types of Wind Turbine Generators, in: Espoo, Finland, 2006. 
[9] J.C. Ausin, D. Navarro Gebers, B. Andresen, Fault Ride-Through Capability Test Unit for Wind Turbines, Wind Energy. Special Issue: Grid Integration of Wind Power Generating Plants. 11 (2008) 3-12.

[10] J.I. González Llorente, F. Miguel Linares, Dispositivo Generador de Huecos de Tensión, WO2006106163 A1, 2006.

[11] International Electrotechnical Commission, IEC 61400-21:2008. Wind turbines - Part 21: Measurement and Assessment of Power Quality Characteristics of Grid Connected Wind Turbines, (2008).

[12] Asociación Empresarial Eólica, Procedimiento de Verificación, Validación y Certificación de los Requisitos del P.O.12.3. sobre la Respuesta de Instalaciones Eólicas y Fotoyoltaicas ante Huecos de Tensión, (2012). https://www.aeeolica.org/uploads/documents/2105-pvvc-n10.pdf (accessed May 18, 2017).

[13] J. Langstädtler, B. Showe-von Der Brelie, M. Schellschmidt, S. Schrobsdorff, J. Scheffer, C. Kahlen, Relevance of High-voltage-Ride-Through Capability and Testing, in: Lyon, 2015.

[14] Centro Nacional De Energías Renovales (CENER), Laboratorio de Ensayo de Aerogeneradores - Instituto del viento, (n.d.). http://www.cener.com/documentacion/LaboratorioEnsayoAerogeneradores.pdf.

[15] C. Wessels, R. Lohde, F. W. Fuchs, Transformer Based Voltage Sag Generator to Perform LVRT and HVRT in the Laboratory, in: IEEE, Ohrid, Macedonia, 2010: pp. T11-8-T11-13. doi:10.1109/EPEPEMC.2010.5606830.

[16] L. Dongyu, Z. Honglin, X. Shuai, Y. Geng, A New Voltage Generator Based on Power Electronics Devices, in: IEEE, Hefei, China, 2010: pp. 584-588.

[17] A.D. Alonso Herranz, S. Borroy Vicente, M.P. Comech Moreno, M.Á. Cova Acosta, Device that Generates Electrical Disturbances, WO2012113951 A1, 2012.

[18] C.A. Platero, C. Veganzones, F. Blázquez, D. Ramírez, S. Martínez, J. Á. Sánchez, J. Rodríguez, N. Herrero, Banco de Ensayo de Equipos eléctricos, Generadores o Consumidores, frente a Huecos de Tensión, ES 2325902 B2, 2008.

[19] E.R. Collins, R.L. Morgan, A Three-Phase Sag Generator for Testing Industrial Equipment, IEEE Transactions on Power Delivery. 11 (1996) 526-532. doi:10.1109/61.484138.

[20] A. Uphues, K. Notzold, R. Wegener, K. Fink, M. Bragard, R. Griessel, S. Soter, Inverter Based Test Setup for LVRT Verification of a Full-scale 2MW Wind Power Converter, in: Lille, France, 2013. doi:10.1109/EPE.2013.6634752.

[21] K. Oranpiroj, S. Premrudeeprechacharn, M. Ngoudech, W. Mungjai, K. Yingkayan, T. Boonsai, The 3-Phase 4-Wire Voltage Sag Generator Based on abc Algorithm, in: IEEE, Pattaya, Chonburi, Thailand, 2009. doi:10.1109/ECTICON.2009.5136971.

[22] R. Lohde, F. W. Fuchs, Laboratory Type PWM Grid Emulator for Generating Disturbed Voltages for Testing Grid Connected Devices, in: IEEE, Barcelona, Spain, 2009.

[23] X. Yan, B.Zhang, S. Wang, Three-phase Voltage Sag Generator, CN101887074 B, 2010.

[24] R.A. Jerin, P. Kaliannan, U. Subramaniam, Testing of Low Voltage Ride Through Capability Compliance of Wind Turbines - A review, International Journal of Ambient Energy. (2017) 1-7. doi:10.1080/01430750.2017.1340337.

[25] C. Saniter, J. Janning, Test Bench for Grid Code Simulations for Multi-MW Wind Turbines, IEEE Transactions on Power Electronics. 23 (2008) 1707-1715. 
[26] P. Koralewidz, P. Jörg, E. Guidi, Power Electronic Grid Simulator - Platform of drives and power quality products for power electronics testing, (2014). https://www.nrel.gov/grid/assets/pdfs/second_grid_sim_koralewicz.pdf (accessed August 23, 2017).

[27] V. Gevorgian, P. Koralewidz, R. Wallen, E. Muljadi, Controllable Grid Interface for Testing Ancillary Service Controls and Fault Performance of Utility-Scale Wind Power Generation, in: National Renewable Energy Laboratory (NREL), 2016.

[28] N.I. Espinoza, Grid code testing of wind turbines by voltage source converter based test equipment, Thesis for the degree of licentiate of engineering, Chalmers University of Technology, 2015.

[29] University of Strathclyde, Wind resource: Utilizing hydrogen buffering. System costs., (2017). http://www.esru.strath.ac.uk/EandE/Web_sites/08-09/Hydrogen_Buffering/Economics\%20\%20System\%20costs.html.

[30] International Renewable Energy Agency (IRENA), Typical onshore wind farm installed cost breakdown, (n.d.). http://costing.irena.org/charts/wind.aspx (accessed August 22, 2017).

[31] V. Yaramasu, B. Wu, Basics of the wind energy conversion systems (WECS), Model Predictive Control of Wind Energy Conversion Systems. 1 (n.d.) 29.

[32] Richard Piwko, Einar Larsen, Carl Wegner, Variable Frequency Transformer - A New Alternative for Asynchronous Power Transfer, in: IEEE, Durban, South Africa, 2005.

[33] A. Merkhouf, P. Doyon, S. Upadhyay, Variable Frequency Transformer-Concept and Electromagnetic Design Evaluation, IEEE Transactions on Energy Conversion. 23 (2008) 989-996. doi:10.1109/TEC.2008.2001460.

[34] L. W.Thompson, Electrical Control System, US1844704 A, 1932.

[35] F.J. Champlin, Electrical Regulator, US2324822 A, 1942.

[36] H. J. Hall, Automatic Voltage Control of Electrostatic Precipitator with Saturable Reactor, US2742104 A, 1953.

[37] L. H. Carr, The Use of the Induction Regulators in Feeder Circuits, Journal of the Institution of Electrical Engineers. 63 (1925) 864-873.

[38] W. E. M. Ayres, The Application of the Induction Voltage Regulator, Journal of the Institution of Electrical Engineers. 69 (1931) 1208-1218.

[39] J. Merino, P. Mendoza-Araya, C. Veganzones, State of the Art and Future Trends in Grid Codes Applicable to Isolated Electrical Systems, Energies. 7 (2014) 7936-7954. doi:10.3390/en7127936.

[40] Red Eléctrica de España (REE), P.O.12.2. Instalaciones Conectadas a la Red de Transporte de Energía Eléctrica: Requisitos Mínimos de Diseño, Equipamiento, Funcionamiento y Seguridad y Puesta en Servicio, (2006).

[41] Red Eléctrica de España (REE), Requisitos Técnicos de las Instalaciones Eólicas, Fotovoltaicas y Todas Aquellas Instalaciones de Producción Cuya Tecnología no Emplee un Generador Síncrono Conectado Directamente a Red, (2008). https://www.aeeolica.org/uploads/documents/4535-separata-del-borrador-de-po122.pdf.

\section{Authors}



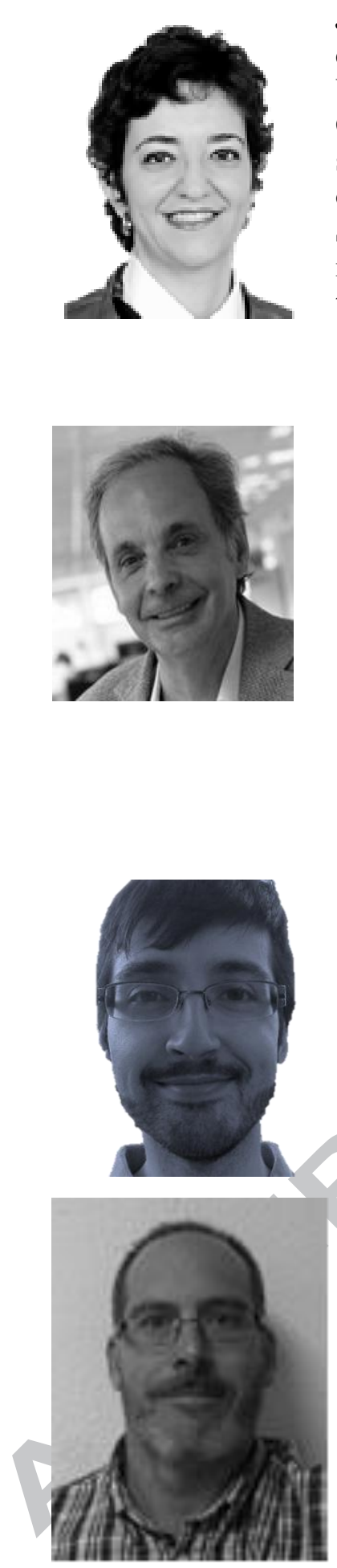

Julia Merino received the Dipl. Degree in Industrial Engineering, the M.S. degree in Electrical Engineering and the $\mathrm{PhD}$ degree from the Technical University of Madrid, Spain, in 2010, 2012 and 2015. She is with the Smart Grids and Energy Storage Area of TECNALIA, where is participating in several FP7/H2020 EU-funded projects. Her research interests are focused on renewable energies, microgrids/smart grids and distributed generation. She has published a number of JCR papers, participated in several international conferences and holds one patent. She is the current Chair of the IEEE Women in Engineering (WIE) Spain Section.

Carlos Veganzones received the B.Sc. degree in industrial electrical engineering from the Polytechnic University of Catalunya, Barcelona, Spain, in 1982, and the Ph.D. degree in industrial engineering from the Polytechnic University of Madrid, Madrid, Spain, in 1990. Since 1985, he has been with the Department of Electrical Engineering, Polytechnic University of Madrid, where he has been a Full Professor since 1992. He has been involved in more than 30 research projects related with power electricity generation with renewable energy. He has directed five Ph.D. theses and is the Director of the research group "Power Generation with Wind Energy". He has co-authored numerous publications, including eight book chapters, 11 JCR papers, and multiple international conferences. He is the co-holder of five patents.

Roberto Alvaro-Hermana received the Industrial Eng. Degree,the M.S. degree and the Ph.D. in Electrical Engineering in 2011, 2013 and 2017 from Technical University of Madrid (UPM). He is also with the Orkestra Basque Institute of Competitiveness. His current research focuses on Energy Markets and EV applications.

Jesús Fraile-Ardanuy received the Telecommunication Eng. Degree from Technical University of Madrid (UPM), Madrid in 1996 and the Ph.D. degree from UPM, Spain, in 2003. He is an Associate Professor at ETSI Telecomunicación-UPM. He is the author of twelve books, more than 50 articles in peer reviewed journals and international conferences. His research interests include applications of intelligent control to renewable energy generation and the integration of electric vehicles on the grid. 
- Novel testing device for distribution grid technologies' certification

- Able to reproduce voltage, frequency and controlled phase jumps simultaneously

- Based on electrical machines and managed by a simple control system to make it easily handy by the user

- Easily replicable, scalable and based on electrical machines that can be standardized in order to be commercially competitive 